Tropical Journal of Pharmaceutical Research April 2017; 16 (4): 873-876

ISSN: $1596-5996$ (print); 1596-9827 (electronic)

(C) Pharmacotherapy Group, Faculty of Pharmacy, University of Benin, Benin City, 300001 Nigeria.

All rights reserved.

Available online at http://www.tjpr.org

Original Research Article

http://dx.doi.org/10.4314/tjpr.v16i4.18

\title{
Effect of Zicao ointment on second-degree burns in rats
}

\author{
Hong-bin Luo ${ }^{1}$, Yi Cao', Mao-can Tao ${ }^{1}$, Xiao-hong Yang ${ }^{1}$ and You-li Wang ${ }^{2 *}$ \\ ${ }^{1}$ Department of Dematology, The First Affiliated Hospital of Zhejiang Chinese Medical University, Hangzhou 310000 , \\ ${ }^{2}$ Department of Dematology, Zhuji Hospital of Traditional Chinese Medicine, Zhuji 311800, Zhejiang Province, China
}

*For correspondence: Email: wangyouli494@sina.com; Tel: +86 057587979091

Revised accepted: 5 March 2017

\begin{abstract}
Purpose: To investigate the healing effect of Zicao Ointment (ZCO) on second-degree burns in rats. Methods: Male Sprague Dawley (SD) rats, weighing 200 - $220 \mathrm{~g}$, were subjected to deep seconddegree skin burns by electrical scald instrument. The animals were divided into three groups as follows: (1) second-degree burns (control) group, (2) burns treated with $1 \%$ silver sulfadiazine (SSD) group, and (3) second-degree burns treated with ZCO group. On days 3, 7 and 14 following administration of the drug or ZCO, wound area and histopathological changes of rat epidermis were evaluated for the various groups.

Results: On day 14, mean wound area of ZCO treatment group $\left(0.28 \pm 0.04 \mathrm{~cm}^{2}\right)$ was significantly smaller than that of the control rats $\left(2.63 \pm 0.19 \mathrm{~cm}^{2}, p<0.01\right)$. Histological results indicate that inflammatory cells disappeared and were replaced by new granulation tissue by day 14 in the group treated with ZCO. Compared with SSD group rats, the inflammatory cells decreased and fibroblast and granulation tissues increased significantly in burnt rats treated with ZCO.

Conclusion: Zicao Ointment is effective for the treatment of second-degree burns in rats and may be suitable for clinical therapy of second-degree burns.
\end{abstract}

Keywords: Zicao ointment, Second-degree burns, Healing, Rat epidermis, Silver sulfadiazine

\begin{abstract}
Tropical Journal of Pharmaceutical Research is indexed by Science Citation Index (SciSearch), Scopus, International Pharmaceutical Abstract, Chemical Abstracts, Embase, Index Copernicus, EBSCO, African Index Medicus, JournalSeek, Journal Citation Reports/Science Edition, Directory of Open Access Journals (DOAJ), African Journal Online, Bioline International, Open-J-Gate and Pharmacy Abstracts
\end{abstract}

\section{INTRODUCTION}

Every year, millions of people suffer major disabilities or even death from burns, caused by hot water, flame and boiling oil. People suffer from burns due to domestic and industrial accidents, which along with enormous cost of treatment, cause mortality and considerable morbidity [1]. According to the World Health Organization (WHO), there were 300,000 deaths worldwide due to burns in 2012, with $96 \%$ of these deaths occurring in developing countries [2]. Burns are one of the health problems in modern societies associated with irreparable damage to patients and family relationships [3].

Currently, silver sulfadiazine is the most used topical treatment for burns due to its potent antimicrobial efficacy. However, it was found that silver gets absorbed systemically, posing problems on prolonged use and systemic complications such as neutropenia, methemoglobinemia and renal toxicity [4]. Therefore, finding more effective agents with fewer side effects for burns is imperative.

Zicao Ointment, which is composed of Lithospermum erythrorhizon and Polistes mandarinus Saussure, is a traditional Chinese medice for treating burns. Lithospermum erythrorhizon has been used in treatment of inflammation, infection, jaundice, skin burns and hyperlipemia in China and Japan [5]. Several studies have evaluated the antioxidant capacity 
of Lithospermum erythrorhizon extract [6,7] and its anti-inflammatory activities, such as the inhibition of NF-kB [8]. In the present study, the healing effect of Zicao Ointment on deep seconddegree burn wounds in rats was investigated.

\section{EXPERIMENTAL}

\section{Materials}

The herbal samples of Zicao ointment were collected from Enshi City, Hubei Province in China in May 2015. Taxonomic identification of the plant materials was performed by Prof Neng Liu, College of of Pharmacy of Zhejiang Chinese medical University, China. A voucher specimen (no. ZCO 201505006) was deposited in the College of pharmacy of Zhejiang Chinese Medical University, China for future reference.

\section{Animals and model preparation}

Female Wistar rats weighing 180 - $200 \mathrm{~g}$ were obtained from Zhejiang Center for Disease Control and Prevention, Hangzhou, Zhejiang. The rats had free access to feed and were allowed to acclimatize for at least one week before use. The animal experiment was approved by the Animal Care and Use Committee of Zhejiang Chinese Medical University (approval reference no. 20040503) and was carried out in compliance with the Directive 2010/63/EU on the handling of animals used for scientific purposes [9].

Ethyl carbamate solution was used for anesthetizing the rats after the rat hair was shaved. The top of electrical scald instrument (Changhai Hospital of Second Military Medical University, China) was pressed on the skin at the back of the rat for $12 \mathrm{~s}$ at $80^{\circ} \mathrm{C}$. In this way, the second-degree burn model was prepared.

\section{Experimental groups and treatments}

All rats were randomly divided into three groups of thirty-five rats each: second-degree burn model group, silver sulfadiazine-treated group and ZCO-treated group. All the animals in the second-degree burn model, silver sulfadiazinetreated and ZCO-treated groups received a deep second-degree burn. Silver sulfadiazine cream (1 $\%, \mathrm{w} / \mathrm{w})$ was used as the standard drug.

In a preliminary study, the dose-response properties of ZCO and silver sulfadiazine were examined to determine the optimal dose, and 0.4 g SSD or $1 \mathrm{~mL}$ ZCO per wound were confirmed as the most effective dosage for the wound healing. One $\mathrm{mL}$ of $\mathrm{ZCO}$ or $0.4 \mathrm{~g}$ of SSD was applied slowly with cotton bud to the burn wound area and extended slightly outside the wound area to ensure inclusion of the wound edges. The treatments were repeated twice daily for 14 days. The first application was done directly after the injury. The control group did not receive any treatment for 14 days. The wound remained exposed after the treatment.

\section{Average wound area measurement}

On days 3,7 and 14, following treatment, average wound areas of the control, SSD and ZCO group rats were measured. The wounds were photographed with a digital camera in order to calculate the wound surface areas (WSA) with Autocad software 2010 (made by Autodesk Co. Ltd). The change in wound surface area in a given day $\left(W A_{\text {day-x }}\right)$ was expressed as a percentage of the wound area on the second day (WSA day-2) using Eq 1.

$W S A=\left\{\left(W A_{\text {day }-2}-W S A_{\text {day }-x}\right) / W S A_{\text {day }-2}\right\} 100 \ldots$ (1)

\section{Histological study}

Wound skin tissue samples were taken, using a scalpel, from the control, SSD and ZCO groups on days 7 and 14 for histological observation. The skin tissues were fixed with $10 \%$ formalin. After fixation, the samples were embedded in paraffin, cut into $3 \mathrm{~mm}$ frozen sections with a cryostat microtome, and then stained with hematoxylin and eosin reagent. A collagen fiber, inflammatory cell, blood vessel and granulation tissue of the skin tissues were examined under a microscope.

\section{Statistical analysis}

The values are expressed as mean \pm SEM. Multiple group comparisons were performed by one-way analysis of variance (ANOVA) using SPSS 16.0 followed by Dunnett's test to detect intergroup differences. $P<0.05$ was considered statistically significant.

\section{RESULTS}

\section{Wound healing test}

The wound area of burnt rats decreased progressively when applied with SSD or 120 $\mathrm{mg} / \mathrm{mL}$ ZCO treatment. The wounds treated with ZCO healed more quickly than those of the control group. The mean wound area of ZCO group was smaller than that of control groups by day $14(p<0.01)$ (Figure 1). Meanwhile, the average wound area of burnt rats treated with 


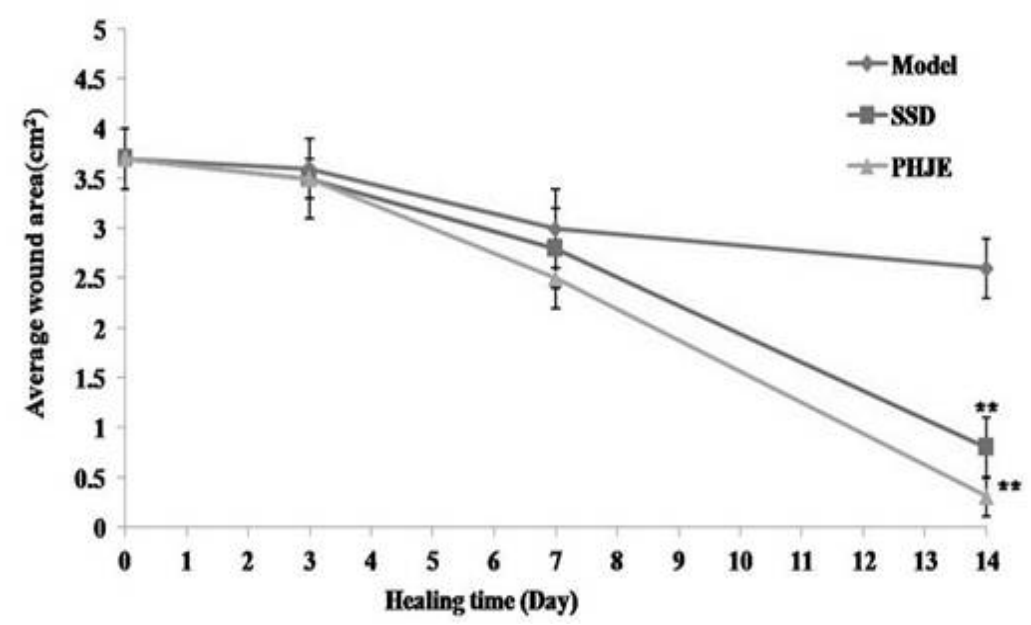

Figure 1: Wound area as a function of time $(n=10)$. Data are expressed as mean \pm SEM. Differences between control (model) and the treated groups were significant $\left({ }^{*} p<0.05\right.$ and $\left.{ }^{* *} p<0.01\right)$ compared to the control (model)

SSD was significantly smaller than that of the control rats on day $14(p<0.01)$.

\section{Histological features}

After a second-degree burn showing muscular and adipose tissues formed, there were neither dermis nor epidermis and infection was absent. Histological findings of the wounded skin, treated with SSD and ZCO on day 7 and 14 are shown in Figure 2. On day 0 , collagen fiber was necrotic, inflammatory cells infiltrated below the striated muscles and vascular engorgement and necrosis were seen in the burn skin of model rats. On day 7 , there was severe infiltration of inflammatory cells and some fibroblast and granulation tissues were found in the burnt skin of the control rats. The inflammatory cells of rat skin treated with SSD or ZCO decreased significantly and fibroblast and granulation tissues increased rapidly. By day 14, inflammatory cells were still seen and some fibroblast and granulation tissues grew in the burnt skin of the control rats. The inflammatory cells disappeared and new granulation tissue, collagen fibers and epithelialization progressed very quickly in rats treated with SSD or ZCO.

\section{DISCUSSION}

Thermal burn injury is still a major cause of death and disability in the world and its healing process is a challenge in modern medicine. Burns on human body may be treated by different methods depending on the extent and severity of the burn. SSD is bactericidal on a wide variety of bacteria, so it is commonly used to prevent and treat infections of second and third degree burns. Recent studies revealed that SSD ointment has positive effects on the proliferation of fibroblasts which are the main source of collagen and fibronectin [10]. However, some reports suggest that silver-based products show side effects during burns treatment $[11,12]$.
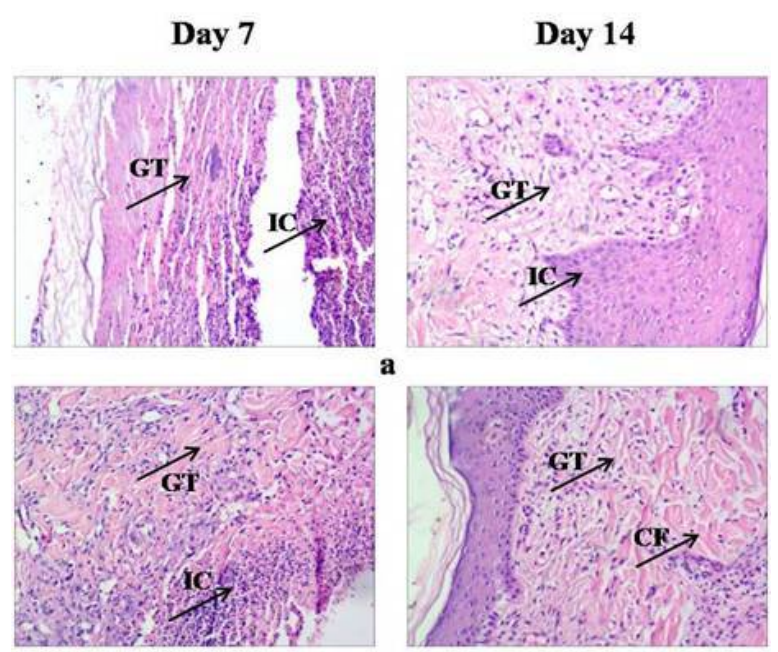

b
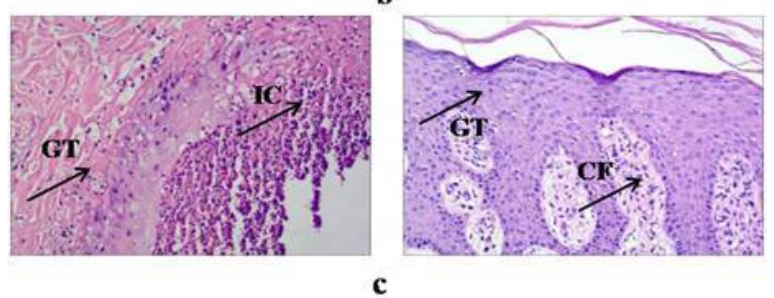

Figure 2: Pathomorphology of rat skin. (a) control, (b) SSD treatment, and (c) ZCO treatment on Day 7 and Day 14 respectively $(100 \times)$; IC = inflammatory cells, $\mathrm{GT}=$ granulation tissues, $\mathrm{CF}=$ collagen fibers

In recent years, there has been a rising trend in natural medicinal products for the local treatment of wounds due to the high costs of traditional drug treatments [13]. Skin integrity is restored by a physiological process aimed at repairing the 
damaged tissues. The healing process proceeds in four phases: hemostasis, inflammation, proliferation and remodeling [14]. The time required for complete healing of deep seconddegree burns, without the application of specific therapeutic agents, can be three to six weeks or more, and a scar tissue may appear [15]. In our study, ZCO accelerated the scab of deep-degree burn wound and prevented infection effectively.

Burn wounds treated with $\mathrm{ZCO}$ recovered well by day 14. However, the wounds of the control group still showed severe inflammatory cell infiltration and the epidermis of the burns was not healed.

\section{CONCLUSION}

The findings of this study reveal that Zicao ointment accelerates healing of second-degree burns in rats, and therefore can potentially be developed into a suitable therapeutic product for burns treatment.

\section{DECLARATIONS}

\section{Acknowledgement}

This study was supported by Traditional Chinese Medicine Science Research Foundation of Zhejiang, China (NO.2015ZB057).

\section{Conflict of Interest}

No conflict of interest associated with this work.

\section{Contribution of Authors}

The authors declare that this work was done by the authors named in this article and all liabilities pertaining to claims relating to the content of this article will be borne by them.

\section{Open Access}

This is an Open Access article that uses a funding model which does not charge readers or their institutions for access and distributed under the terms of the Creative Commons Attribution License (http://creativecommons.org/licenses/by/ 4.0) and the Budapest Open Access Initiative (http://www.budapestopenaccessinitiative.org/rea d), which permit unrestricted use, distribution, and reproduction in any medium, provided the original work is properly credited.

\section{REFERENCES}

1. Nacer KA, Mahlous M, Tahtat D. Evaluation of healing activity of PVA/chitosan hydrogels on deep second degree burn: pharmacological and toxicological tests. Burns 2013; 39: 98-104.

2. Kopp J, Wang GY, Horch RE. Ancient traditional Chinese medicine in burn treatment: a historical review. Burns 2003; 29: 473-478.

3. Edelman LS. Social and economic factors associated with the risk of burn injury. Burns 2007; 33: 958-965.

4. Shanmugasundaram N, Uma TS, Lakshmi TSR, Babu M. Efficiency of controlled topical delivery of silver sulfadiazine in infected burn wounds. J Biomed Mater Res A 2009; 89: 472-482.

5. Peng $W$, Qin $R$, Li X. Botany, phytochemistry, pharmacology, and potential application of Lithospermum erythrorhizon: A review. J Ethnopharmacol 2013; 148: 729-745.

6. Masaki H, Sakaki S, Atsumi T, Sakurai H. Active-oxygen scavenging activity of plant extracts. Biol Pharm Bull 1995; 18: 162-166.

7. Hsu CY, Chan YP, Chang J. Antioxidant activity of extract from Lithospermum erythrorhizon. Biol Res 2007; 40: 13-21.

8. Eve EB, Phillip G, James $L H$, Louise W, Diane $K H$. Topical anti-inflammatory activity of Lithospermum erythrorhizon extract in the TPA model of mouse ear inflammation. J Inflamm 2008; 5: 1-4.

9. European Commission [homepage on the internet]. Directive 2010/63/EU on the protection of animals used for scientific purposes [cited 2013 Jan 16]. Available from:http://ec.europa.eu/environment/chemicals/lab_ani mals/legislation_en. $h$ tm.

10. Coelho JM, Antoniolli AB, Nunese SD. Effects of silver sulfadiazine, ipêroxo (Tabebuia avellanedae) extract and barbatimão (Stryphnodendron adstringens) extract on cutaneous wound healing in rats. Rev Col Bras Cir 2010; 37: 45-51.

11. Burd A, Kwok CH, Hung SC, Chan HS, Gu H, Lam WK, Huang L. A comparative study of the cytotoxicity of silver-based dressings in monolayer cell, tissue explant, and animal models. Wound Repair Regen 2007; 15: 94104.

12. Aijuan L, Jixiang C, Weiming Z, Tao J, Xiaohua Z, Qianqun G. Antibacterial activity of gallic acid from the flowers of Rosa chinensis Jacq. Against fish pathogens. Aquaculture Res 2007; 38: 1110-1112.

13. Lee JA, Jeong HJ, Park HJ, Jeon S, Hong SU. Acupuncture accelerates wound healing in burnedinjured mice. Burns 2011; 37: 117-125.

14. Pazyar N, Yaghoobi R, Rafiee E, Mehrabian A, Feily A. Skin wound healing and phytomedicine: a review. Skin Pharmacol Physiol 2014; 27: 303-310.

15. Johnson RM, Richard R. Partial-thickness burns: identification and management. Adv Skin Wound Care 2003; 16: 178-187. 